\title{
Feminist Research
}

Review Article

\section{Women Authorship of Scholarly Publications in STEMM: Authorship Puzzle}

\section{Vijay S. Bhagat*}

Post-graduate Research Centre in Geography, Agasti Arts, Commerce and Dadasaheb Rupwate Science College, Akole - 422601, Ahmednagar, Maharashtra (India)

\begin{abstract}
The continued underrepresentation of women in scholarly activities slows down the scientific progress of any country. Several studies have analyzed the women representation in authorship of scholarly publications in Science, Technology, Engineering, Mathematics and Medicine (STEMM). Women account only 30\% of overall authorship of scholarly articles. Prestigious authorships like first-, last- and corresponding authors also show significant underrepresentation of women. Women as first authors are significantly increasing since last decades; however, growth of last authors is not significant and share of corresponding authors not changed. Women show low overall impact of scholarly publications due to lower productivity but not for quality of publication. This gender authorship puzzle can be solved by adopting gender responsive planning and management. Therefore, systematic efforts to understand the gender disparities in scholarly publications, authorship citations and collaborations require for achieving significant positive change in the share of women in academic authorship, impact and career. The field is new, active, attractive and interesting area of research to achieve gender equality in scientific research and publications for social welfare.
\end{abstract}

(ㄷ) 2018 GATHA COGNITION ${ }^{\circledR}$ All rights reserved.
Article history

Received: 14 April 2019

Accepted: 11 June 2019

Key words

Authorship Puzzle;

Authorship;

Feminism;

Gender;

Publications;

Research;

Science;

Women.

Processing Editor(s)

Fatima Sadiqi

Souad Slaoui

\section{INTRODUCTION}

Science, Technology, Engineering, Mathematics and Medicine (STEMM) are the most driving elements of society moving towards bright future for social and economic development (Ghias et al., 2015). Women are approximately half of the population of any country. They have invented many scientific treaties and equipped to the society for formation and development of human culture (Nehere, 2017). However, since the centuries women considered unfit for research and intellectual activities (Cole and Zuckerman, 1984). Scholars and general public believed in women are physically, intellectually and emotionally frail. Women are neglected from mainstream activities and involved in unpaid domestic laborer. They are facing many personal, familial and social problems. Optimal participation of women in research activity and planning will be helpful to solve these problems. Very recently universities are widely opened for women and enrolled them for higher education and participated in modern research activities (West, 2013).

Several studies have been conducted for analysis of women representation in authorship of scholarly publications and research activities in STEMM. They have reported considerable progress in gender equality in the field (Jagsi et al., 2006; National Research Council (NRC), 2010; Gender in the Global Research Landscape (GGRL), 2017). Gender disparities in academic activities are decreasing since last few years for grant funding, hiring, acceptance of manuscripts at scholarly journals and productivity (Larivie're et al., 2011; NRC, 2010; West, 2013; Sheltzer and Smith, 2014). NRC (2010) has also pointed gender equality for nomination for national and international honors and awards and salary at lower level professors. However, women have lesser institution support and access to

\footnotetext{
Author address for correspondence
}

Post-graduate Research Centre in Geography, Agasti Arts, Commerce and Dadasaheb Rupwate Science College, Akole 422601, Ahmednagar, Maharashtra (India).

Tel.: +919860932949

E-mail: kalpvij@gmail.com (V.Bhagat-Corresponding author) 
equipment and laboratory facilities (NRC, 2010; Duch et al., 2012). Women scientists earn far lesser (25 to $40 \%$ ) than the men in developed countries especially in the field of Physics and Astronomy (Shen, 2013). NRC (2010) reported lesser salary for female full professors than male though they spent more time for professional activities from lower levels. Women need higher performance $(160 \%)$ for successful career (Ghias et al., 2015; Besselaar and Sandström, 2016). This relationship between gender and difference in productivity continued since 1920s (Cole and Zuckerman, 1984). Cole and Zuckerman (1984) have reported only $8 \%$ papers contributed by American women scientists in 1957-58. Academic success and career opportunities fully rely on scholarly publications and participation in scholarly activities like conducting research projects, reviewing and editing the manuscripts, invited talks, chairing the technical sessions in academic discussions, etc. (Dijk et al., 2014).

Several mechanisms have been planned and applied to increase women's participation and minimize gender gap in scholarly activities through increasing productivity, journal placements and citations (Cho et al., 2014). However, large gender disparity is still challenging task to achieve equality in science (Larivière et al., 2013). Few women are at higher academic positions e.g. full professors, chairs, invited speakers and editors. Inequalities in hiring, earning, funding, patenting and satisfying are also observed in almost all countries (Larivière et al., 2013). Women authorship of scholarly articles is fewer than $30 \%$ whereas men authored more than $70 \%$ articles, globally. Similar results have been reported by Long et al. (2015) about authorship in gastroenterologists and Fox et al. (2016) about Journal Functional Ecology (2010-2014).

Only 6\% countries show gender equality in authorship of scientific publications (Larivière et al., 2013). Prestigious authorship positions like first-, corresponding- and last author show underrepresentation of women. Patents authored and registered by women are far less than the men. But share of patents by women is increasing and encouraging in all fields in most of the countries (GGRL, 2017; Lax Martínez et al., 2016). Lesser impact of women researchers is due to lower productivity (Besselaar and Sandström, 2016). Therefore, inequalities between men and women in STEMM remain important topic for feminist studies and policies (Ramos et al., 2015; Besselaar and Sandström, 2016).

Women are leading the progress of countries with lower scientific development with more authorship of scientific publications (Larivière et al., 2013). Therefore, unbiased recruitments of women in scientific community can step up the academic research and development (Sheltzer and Smith, 2014). Active participation of women will be helpful to achieve advancements in academic fields (Moss-Racusin et al., 2012).
The feminist research analyzes the factors controlling the progress of women in the scientific career (Ramos et al., 2015). Second Wave Feminism has attracted public eye towards gender equality in science since 1970 (Bendels et al., 2018). Feminist reforms in culture, education, recruitment, monitoring, publication, etc. will be useful to reduce gender gap in scientific publications (Holman et al., 2018). However, minor evidence based research has conducted for empirical assessment to check the success of these policies (Ghias et al., 2015; Williams, 2018). Reasons for gender difference in authorship of scholarly publications are not clear (Kaufman and Chevan, 2011). The field is new, active and attractive area of research to achieve gender equality in scientific research and publications for social welfare. Therefore, the available literature has been rigorously reviewed and findings of previous research have been reported in this article. These findings can be helpful to prepare policies of any country towards gender equality in scholarly publications in STEMM for women's participation for social welfare.

\section{COLLABORATIONS}

Collaborations in research activities including conducting research projects and writing articles make work more effective and applicable (Wuchty et al., 2007; Ghias et al., 2015). Team produces more effective and high-impact research than the individuals (Wuchty et al., 207). Women produce more research publications in team than the single-authored work as compared to men (Kyvik and Teigen, 1996). They are more collaborative and less competitive in the team which makes them good leaders (Bart and McQueen, 2013). Further, collaborated role-performance in these collaborations presents social status of contributors in social institutions as roles like principal investigator of the project, principal-, corresponding- and last-author of the research reports and articles, invited speakers, chair of the technical sessions in the conferences, etc. (Zuckerman, 1968).

Women academicians have less opportunities of collaboration for research activities (Kegen, 2013) and observed less co-authors in scientific publications (Zeng et al., 2016). Women participated and co-authored patents instead of woman sole authorship (Lax Martínez et al., 2016). However, the patents authored by women are very less than the men (Lax Martínez et al., 2016). Zeng et al. (2016) have reported significantly less women co-authors of scientific publications than the men with less probabilities of repeating co-authorship with previous team

Further, a few women are working as higher level academicians such as full professors, principal investigators, invited speakers and session chairs. Gender inequalities are found in hiring, earnings, funding, satisfaction and patenting research outputs (Conley and Stadmark, 2012; Larivière et al., 2013). Highly qualified male faculties train fewer female faculties in laboratories (Sheltzer and Smith, 2014) and 
have impact on success rate of research proposals by women and number of women principal investigators (Patat and Schwarzschildstr, 2016).

Women show less international collaboration and mobility for research projects (GGRL, 2017). The collaborations for scientific projects and publications are more domestic and contribute more than $70 \%$ of the total publications (Larivière et al., 2013; GGRL, 2017). Larivière et al. (2011) observed the tendency of Canadian women to collaborate with scholars from home- and domestic institutes than cross borders due to motherly and family responsibilities. Ghias et al. (2015) have reported only $7 \%$ women collaborated with women and $10 \%$ women with men collaborators for research publications in engineering, worldwide. However, mixgender collaborated teams are more productive.

Therefore, lack of research collaborations is the major cause of gender difference in scientific publications (Kyvik and Teigen, 1996; Uhly et al., 2017). Uhly et al. (2017) reported more benefits of collaborations to men than the women due to extra workload of child care and family responsibilities (Figure 1). Shen (2013) reported that post-doctoral women scholars leave their career to have children. Ramos et al. (2015) have reported non-linear career path for women due to motherhood and domestic work (Kyvik and Teigen, 1996). Similar observations noted by Kaufman and Chevan (2011) in case of women scientists in Physical Therapy. Therefore, familyfriendly policies are suggested for more women participation in research and publication activities.

\section{AUTHORSHIP}

Many studies have reported large gender gap with lesser women authorship in scientific publications in STEMM especially authorship positions and prestigious journals (Larivière et al., 2013; Caplar et al., 2017; Besselaar and Sandström, 2016; Mueller et al., 2016; GGRL, 2017; Holman et al., 2018). Globally, only $30 \%$ of scientific publications are authored by women (Larivière et al., 2013) with men dominance at prestigious positions as first-, corresponding- and last authorship (West, 2013). Similar results have been reported by Bendels et al. (2018) and Mueller et al. (2016).

Holman et al. (2018) reported 87 out of 115 disciplines show significantly less, $45 \%$ and 23 disciplines show only 5\% women authorship in STEMM. Conley and Stadmark (2012) have reported only $17.3 \%$ female authorship for the biological and chemical sciences, $8.1 \%$ for physical sciences and $3.8 \%$ for Earth and environmental sciences where women participation was $32 \%, 16 \%$ and $20 \%$, respectively. Bornmann et al. (2015) have reported only $13 \%$ of highly cited authors were women with wide variation: $3.7 \%$ (engineering) to $31 \%$ (social sciences). Most biased disciplines show very low improvements in gender equality (Holman et al., 2018).
Number of authors per article has been increased, e. g. authors increased from 2.6 (1985) to 3.9 (2015) in case of 'The Journal of Hand Surgery' (Gu et al., 2017). However, women co-authors of scholarly publications are reported very few than the average (Zeng et al., 2016). Authorship position is very important for social status and career achievements. First author conduct study reported in the paper and last author makes possible work reported without actual work (Tscharntke et al., 2007; Bendels et al., 2018). Last author is considered as a leader of the team (Tscharntke et al., 2007; Haws et al., 2018). Corresponding author prepares the manuscript, responsible for matter reported in the manuscript and keep communication with the editor and publisher during the publication process of the manuscript. Therefore, first-, corresponding and last authorship is more prestigious than the other co-authors. Generally, junior researchers are first and co-authors and senior faculties like supervisors, guides, senior professors, etc. are the last authors (Haws et al., 2018). However, diversity often observed in different countries for allocations of credits to subsequent authors (Tscharntke et al., 2007). West (2013) has reported large gender gap for the first authorship before 1990s, but later this gap slightly reduced in overall proportion and emerged for the last authorship. Further, Bendels et al. (2018) have reported that women contribute $33.1 \%$ of the first, $31.8 \%$ of the co- and $18.1 \%$ of the last authorships and female to male ratio was 1.19 for first, 1.35 for co- and 0.47 for last authorship. Similar observation has reported by Buckley et al. (2014) in case of 'New Zealand Journal of Ecology', women firstauthors were 36\%. Similarly, Long et al. (2015) reported in case of gastroenterology: increase in first authorship of women from $9.1 \%$ in 1992 to $29.3 \% 2012$ and senior women authors from 4.8 to $14.5 \%$ in this period. Filardo et al. (2016) analyzed large authorship data and reported significant growth in women first authorship from $27 \%$ in 1994 to $37 \%$ in 2014 in medical journal. Fox et al. (2016) also show underrepresentation of women authorship (26\%) for articles published in ecology journals. Further, Ouyang et al. (2018) reported $33.1 \%$ contribution of women in authorship of cardiology scientific publications with $26.7 \%$ first and $19.7 \%$ senior authors; only 5\% of top 100 authors with little increase. Women radiologist contributed $20 \%$ of overall authorship, $24.7 \%$ of first authors and $15.2 \%$ senior authors with significant growth in Radiology journals from 1993 to 2013 (Liang et al., 2015).

Haws et al. (2018) and Brinker et al. (2018) show no or little change in share of women authorship of articles published in 'Spine' during 2000 to 2015 and 1985 to 2015, respectively. Further, Filardo et al. (2016) reported declining trends for first authorship of articles published in some of the high-impact medical journal in recent years. Honorary authorship shows significant share $(21 \%)$ in authorship of medical journals and honorary authors are most probably last authors (Fadeel, 2009). Several scholars show lesser growth of senior authorship than the first authors (Liang et al., 2015). 
Significant negative correlation has been observed between impact factor of the journals and women representation as prestigious authorship (Bendels et al., 2018). Ghias et al. (2015) have reported that women publish articles with first authorship in high impactfactor journals but receive fewer citations (Bendels et al., 2018). Review-focused journals also have less women authors than the open access journals. Highimpact journals are considered as widely accessed, read, -cited and prestigious. They publish mainly invited papers and reject many submissions without peer review which is disadvantageous for women (Holman et al., 2018). Double-blind peer-reviewing and editing system with appointments of women editors and reviewers encourage to women authors for quality publications.

Long et al. (2015) have noted minor women authorship of editorials with insignificant growth. Further, Haws et al. (2018) have reported similar qualifications of last men and women authors of articles published in 'Spine'. Corresponding women authors in 'Nature' were only $16 \%$ (Nature, 2018) and no change (14\%) has been reported by Brinker et al. (2018) in case of Spine during 1985 to 2015. Productivity of women not more than 2 articles (Bendels et al., 2018). Women publish less with slower annual growth but cited more in hand- and text-books (Cikara et al., 2012).

More men have been invited for paper submissions (Holman et al., 2018) and received citations more than women (Larivière et al., 2013; Caplar et al., 2017). Women publish very less scholarly articles in expensive fields like high-energy physics (Larivière et al., 2013). Physics reported as most biased field for women authorship with very fewer rate of improvements.
Engineering shows less number of women corresponding authors than the men (GGRL, 2017). Tregenza (2002) has also reported gender difference in acceptance of manuscript for scholarly publication. However, NRC (2010) reported no gender difference in publication of articles in biology, civil engineering, and physics.

Traditionally, women are involved in taking care of families and society which reflect in women authorship from disciplines: nursing, midwifery, speech, language and hearing, education, social work, librarianship and social sciences (Larivière et al., 2013) (Figure 1). GGRL (20017) has reported better representation of women authorship in health and life sciences (Jagsi et al., 2006). More number of corresponding authors was reported for papers published in nursing (GGRL, 2017). However, women show underrepresentation in authorship of publication in disciplines like 'military sciences, engineering, robotics, aeronautics and astronautics, high-energy physics, mathematics, computer science, philosophy, economics' and humanities (Larivière et al., 2013).

Less than $6 \%$ countries show gender equality in authorship of scientific scholarly publication (Larivière et al., 2013). Developed countries like Japan, Germany and Switzerland reported less women authorship than poorer countries in South America and Africa (Holman et al., 2018). Women dominance in authorship of scientific publication observed from poorer countries like Macedonia, Sri Lanka, Latvia, Ukraine, and Bosnia and Herzegovina with lesser scientific research and outputs (Larivière et al., 2013). Holman et al. (2018) noted that demographic parameters like life expectancy,

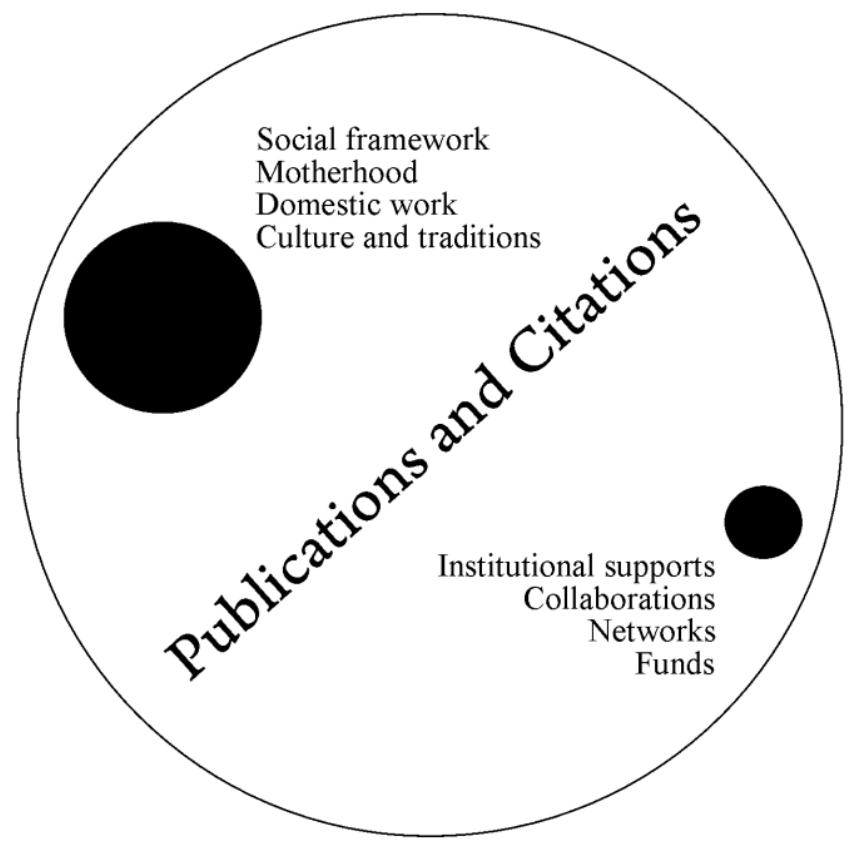

Figure 1. Women authorship space 
child birth at early age of mother, education, number of women in parliament and gender gap in labor force are not correlated significantly with gender gap in authorship of articles in STEMM. However, Kaufman and Chevan (2011) have reported disproportionate share of childcare and domestic work doing by women scientists in status of authorship of articles in Physical Therapy.

Budden et al. (2008) have reported 33\% increase in women authorship after double blind peer-review system adopted by prestigious journal, Behavioural Ecology. However, only $14 \%$ of reviewers were women appointed by the prestigious journal, 'Nature' for assessment of submitted papers (Moss-Racusin et al. 2012).

\section{CITATIONS AND IMPACT FACTOR}

Citation is academic, institutional and social recognition for authors of published and unpublished research articles, papers, reports, etc. Many scholars show fewer publications by women with fewer citations than men. Women publish articles in high impact-factor journals but receive lesser citations than men (Ghias et al., 2015; Holman et al., 2018). Articles authored by multiple authors with woman as key author (first or last author) also receive lesser citations than men (Bendels et al., 2018). Possibilities of article citations are increasing with increasing number of team members (Figg et al., 2006) as 30 for 1-3 authors and more than 80 for articles by team of 15 authors (Bendels et al., 2018). However, collaboration opportunities for women always less than the men minimize the presence of women in academic teams and citations. Holman et al. (2018) have reported negative correlation between journal impact factor and proportion of women authors of the articles published in that journal (Bendels et al., 2018). Therefore, women are not only underrepresented for key authorship of article published in high impact-factor journals but receive fewer citations (high impact) as key authorship.

Three reasons of fewer citations reported as (Bendels et al., 2018): 1) more number of male scientists with strong network than early career female researchers; 2) male scholars cite themselves than the female scholars; and 3) time-delayed citations not considered in half-life citation count. Number of citations of any scholarly article is fully relying on the scientific discipline.

Further, some scholars show no gender difference in per publication citation score (Larivière et al., 2011; Besselaar and Sandström, 2016). No significant difference was observed for citations of single authored articles by women and men. Few studies found more per paper citations for article by women than men (Cole and Zuckerman, 1984). Nevertheless, women receive lesser citations and overall impact of scholarly publication than men due lower productivity not for quality of the publication (Cole and Zuckerman, 1984; Long, 1992).

\section{EDITORS AND PEER REVIEWERS}

Editors are key element for inclusive policy making and applications of any journal (Cole and Zuckerman, 1984). Scholars have reported male dominance in editorial boards and more number of male reviewers (Helmer et al., 2017). Women account only $16 \%$ editorship of the journals in environmental biology, natural resource management and plant sciences during 1985 to 2013 (Cho et al., 2014). Topaz and Sen (2016) have reported that women have contributed only $8.9 \%$ of editorship of journal in mathematics with $7.6 \%$. Similar observations were reported by Morton and Sonnad (2011) in case of 'Journal of Medical Sciences'; Addis and Villa (2003) in case of 'Italian Economics Journal' and Metz and Harzing (2009) in case of journals in management disciplines. Editor prefers to appoint reviewer from same gender (Helmer et al., 2017). However, well representation on women reported in the editorial boards of political sciences journals (Stegmaier et al., 2011). Therefore, Buckley et al. (2014) suggested inclusion of women scholars in editorial boards and reviewers' database of journals to enhance the acceptance of submitted manuscripts. Further, Mauleón et al. (2013) show positive relationship between size of board and woman editor-in-chief with number of women in the board. The inclusion of women in editorial boards will be helpful to solve "gender productivity puzzle" (Cho et $a l ., 2014)$. The situation is slowly improving.

Only $20 \%$ of total reviewers were women scholars in 2012-15 (Lerback and Hanson, 2017). The prestigious journals like 'Nature' has appointed only 14\% women reviewers for assessment of submitted papers (MossRacusin et al., 2012) whereas $29 \%$ reviewers appointed for 'New Zealand Journal of Ecology' were women (Buckley et al., 2014). Budden et al. (2008) have reported $33 \%$ increase in women authorships after double blind peer-review system adopted by prestigious journal, Behavioural Ecology. Research reports show no relation found between publication success rate and gender of authors, reviewers or editors (Buckley et al., 2014; Fox et al., 2016).

Women chair, speakers and attendance in the scholarly conferences were very less than men (Davenport et al., 2014; Pritchard, 2014). Women were asked more questions as compare to men participants but only few questions when session chaired by men (Davenport et al., 2014). Davenport et al. (2014) have reported gender biased selection of speakers and chairs in the conferences. Mengel et al. (2019) reported gender bias teaching evaluation by students in universities which discouraging the junior women faculties and affecting the confidence and relocate the resources away. Teaching skills of these faculties are equally competent to the male faculties. More research publications and citations will improve the high profile academic career of women scientists and scholars. 


\section{PRESENT AND FUTURE TOWARDS GENDER EQUALITY}

The continued underrepresentation of women in scholarly activities slows down the scientific progress of any country, region or human society (Mavriplis et al., 2010; Sheltzer and Smith, 2014). Women have equal abilities to men for all types of work (James and Drakich, 1993). James and Drakich (1993) have proved no gender difference in academic talk. However, biased stereotype belief in society discourages women to pursue their prestigious career (Bian et al., 2017). Duch et al. (2012) have proved significant relationship between gender difference with resource allocation and gender difference in publication rate. No or little change has been reported by Haws et al. (2018) and Brinker et al. (2018) about share of women authorship of articles published in Spine during 2000-2015 and 1985-2015, respectively. Scholars are worried about continuous gender disparity in scholarly authorship (Cikara et al., 2012).

Honorary authors always listed as last author and they contribute $21 \%$ share in authorship of medical journals (Fadeel, 2009). This share of women in last authorship nullifies the possibilities of honorary authorship for women.

Women are leading progress in countries with lower scientific development with more authorship in scientific publications (Larivière et al., 2013). Therefore, unbiased recruitments of women in scientific community can step up the academic research and development (Sheltzer and Smith, 2014). Active participation of women will be helpful to achieve advancement in academic science (Moss-Racusin et al., 2012). No country can afford to neglect half of the intelligence (Larivière et al., 2013). Major findings of the study are:

1. Since the centuries women considered unfit for research and intellectual activities. They have historically less support and access to equipment and facilities for research activities.

2. Several studies show underrepresentation of women in authorship of scholarly articles in STEMM. Women authorship is fewer than $30 \%$.

3. Only 6 countries show gender equalities in scientific publications (Larivière et al., 2013).

4. Prestigious authorship positions like first-, corresponding- and last author show underrepresentation of women.

5. Junior researchers are first authors show large gender gap with decreasing trends from last two/three decades.

6. Senior faculties like supervisors, guides, senior professors, etc. are the last authors. Women last authors are very less than men.
7. Some scholars show decreasing trends of first women authorship for high impact factor journals.

8. Women corresponding authors are very few with no growth in share of overall corresponding authorship (Brinker et al., 2018).

9. High impact-factor journals publish invited papers (Holman et al., 2018).

10. Women authorship of editorials is less with insignificant growth rate (Long et al., 2015).

11. Underrepresentation of women varies according to nature of discipline. Most biased disciplines show very low improvements in gender equality (Holman et al., 2018).

12. Women publish less articles in disciplines like military sciences, engineering, robotics, aeronautics and astronautics, high-energy physics, mathematics, computer science, philosophy, economics and humanities with fewer rate of improvement (Larivière et al., 2013; GGRL, 2017).

13. Better representation of women is reported in the journals of health and life sciences (Jagsi et al., 2006; GGRL, 2017).

14. Women dominance in authorship of scientific publications was observed from poorer countries like Macedonia, Sri Lanka, Latvia, Ukraine, and Bosnia and Herzegovina.

15. Lack of research collaborations with different collaboration patterns and networks is important cause of less scientific publications by the women (Kyvik and Teigen, 1996; GGRL, 2017).

16. Team produces more effective and high-impact research and publications but women show underrepresentation in collaborations.

17. Women receive fewer citations than men. Citations increase with number of co-authors and women have less network and collaborations.

18. Women show negative relationship between journal impact factor and proportion of women authors of the articles published in that journal (Holman et al., 2018; Bendels et al., 2018).

19. No gender difference found in per publication citation score (Larivière et al., 2011; Besselaar and Sandström, 2016) and citations of single authored articles by women and men.

20. Lesser publications by women in high impactfactor journals are not related to rejection of submitted manuscripts but due to lesser submissions (Bendels et al., 2018).

21. Journal editorial boards show very little number of women and appoint more men reviewers for assessment of submitted manuscripts (Helmer et al., 2017). 
22. The inclusion of women in editorial boards will be helpful to solve "gender productivity puzzle" (Cho et al., 2014).

23. Double-blind peer reviews of scholarly manuscripts increase the representation of authorship of scholarly publications (Budden et al., 2008).

24. Lesser number of publications by women scholars observed with lesser co-authorship (Zeng et al., 2016).

25. Patriarchal culture effects the women participation in scientific activities (Zeng et al., 2016).

26. No relation found between publication success rate and gender of authors, reviewers or editors (Bendels et al., 2018).

27. Feminist reforms in education, monitoring and academic publication will be helpful to minimize gender gap in scientific publications (Holman et al., 2018).

28. Family-friendly policies are suggested for more women participation in research and publication activities.

29. Childcare and motherhood are major limitations of women for collaborations and scientific publications (Kyvik and Teigen, 1996; GGRL, 2017).

30. Biased stereotype belief in society discourages women to pursue prestigious career (Bian et al., 2017).

31. Scholars are worried about continuous gender disparity in scholarly authorship (Cikara et al., 2012).

32. Gender responsive policies for equality should consider social, cultural and organizational factors influencing women participation in scientific contributions (Ghias et al., 2015).

Ceci and Williams (2011) have noted misplaced efforts for sex discrimination in reviewing, interviewing and hiring. Scholars like Fox et al. (2016), Bendels et al. (2018), etc. reported main factor of lesser women authorship is not 'rejection' of manuscript but lower productivity. Ceci and Williams (2011) have rejected the claims of discrimination against women in manuscript reviewing as:

1. Manuscript rejected by journals for quality work instead of sex discrimination.
2. Journals have adopted blind reviewing process then identification of sex for discrimination become nullify for acceptance of manuscript publication.

3. Women are successful in publication as men when resources and characteristics are similar.

Women submit fewer manuscripts to the journals and 'productivity puzzle' deal with gender differences in scientific abilities, resources allocations and choice (Besselaar and Sandström, 2016). Ceci and Williams (2011) focused on social intervention for correction of historical problems of gender discrimination through more participation of women in science, technology, engineering and mathematics (Ceci and Williams, 2011). Solving underrepresentation of women requires focusing on education and policy changes towards equality. Some of the scholars are satisfied for solving the discrimination against women in science. However, many studies and observations are not supporting to the hypothesis that 'disparities in abilities' within men and women (Besselaar and Sandström, 2016). It is proved that discriminative social structures, traditions and culture are regulating them for dwarfing their natural abilities (Figure 2).

Journals accept manuscripts for publication for 'scientific quality' instead of 'sex' of the authors. Duch et al. (2012) have reported relationship between risk associated with academic career and gender difference in publication. Motherly responsibilities like childcare and domestic work may translate in less time for research activities and less performance in early career stages (Kyvik and Teigen, 1996; Kaufman and Chevan, 2011; Besselaar and Sandström, 2016). However, disparity in resource allocations and responsibilities in the family within women and men have deep roots in discriminative culture, traditions and social structure of any region. Domestic labor and child caring are not 'self-selection' but socially selected and allocated responsibilities. Further, some studies show no relation between less performance of women in science and parenthood (Stack, 2004; Besselaar and Sandström, 2016). 'American Association of University Women' has reported factors of underrepresentation of women: 1) negative stereotypes image about abilities, 2) academic and professional environment favorable to unconscious gender bias (Hill et al., 2010). Stack (2004) showed that quality of 'research University' and efforts in term of working hours as leading predictor of productivity. However, relationship between research productivity and motherhood and domestic activities should be analyzed with reference to geographic regions. 


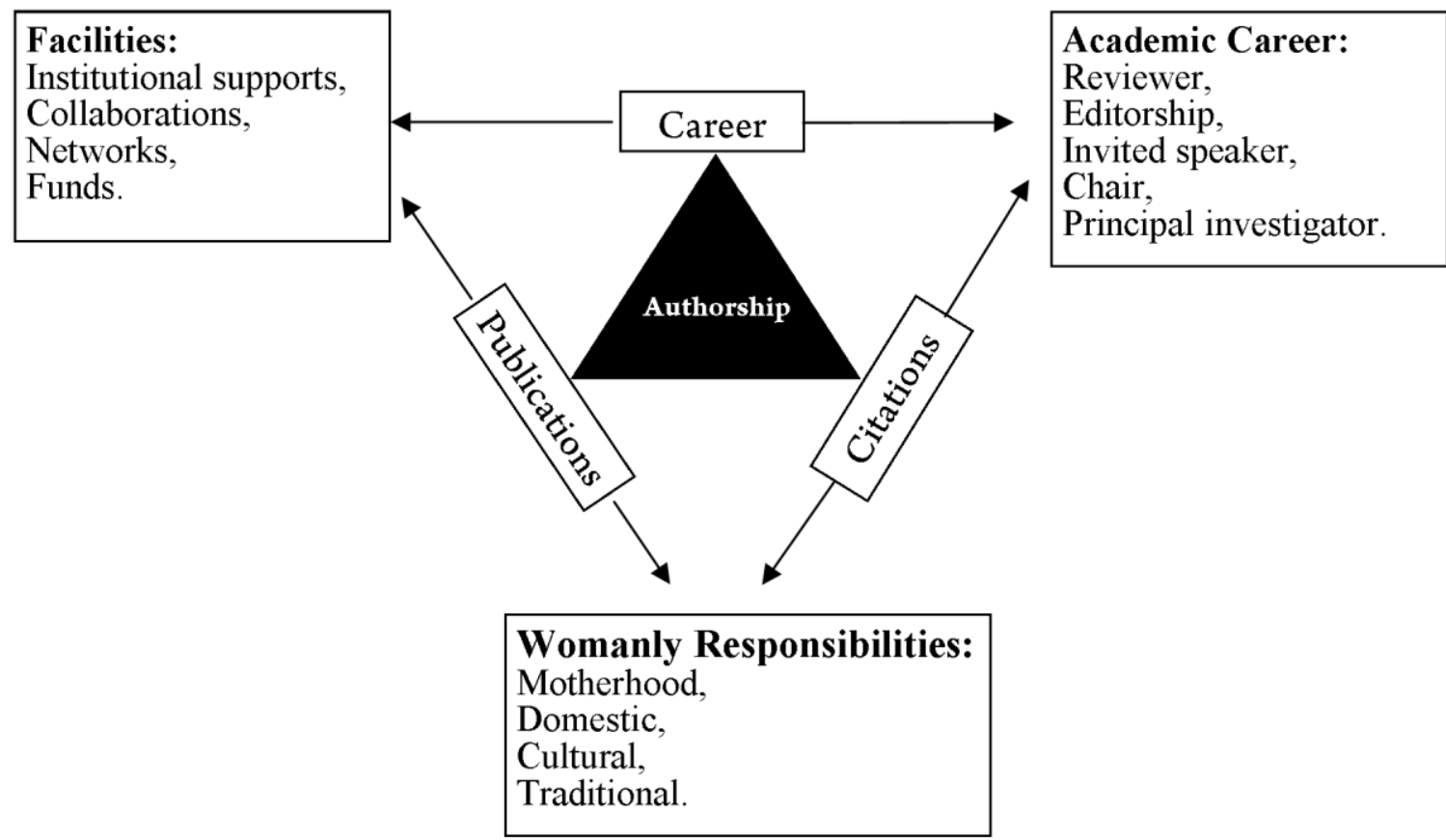

Figure 2. Women authorship puzzle

Neglecting women for author credits is an important issue in scholarly publication and career progress of women community. Four methods for author credit allocation have been reported (Tscharntke et al., 2007): 1) Sequence-determines-credit (SDC) approach, 2) equal contribution (EC) norms, 3) first-last-authoremphasis (FLAE) and 4) per cent-contribution-indicated (PCI). SDC reflects the declining importance of relative contributions by the authors. EC shows equal distribution of author credits and authors appear alphabetical sequence. Great importance of last author is well established in FLAE. PCI is qualified credit evaluation based on combination SDC and EC. Verhagens et al. (2003) have suggested Quantitative Uniform Authorship Declaration (QUAD) to identify the contribution of author rapidly and easily. Tscharntke et al. (2007) have suggested mentioning the explicit indication of method used for evaluation to avoid misinterpretation. Therefore, clearly mentioned simple method of weighing author rank based intellectual activities in publication with quantitative techniques will be beneficial to avoid the credit neglect (Rahman et al., 2017) for women authors. Qualitative and transparent method of evaluation can be helpful to reduce biasness (Verhagens et al., 2003; Weltzien et al., 2006). Rahman et al. (2017) have listed the detail activities involved in preparation of research paper as: formulation of the initial research proposal, review of literature, designing research methodology, technical guidance, preparation instrumental set, data collection, analysis and interpretation, writing the manuscript, revision of the manuscript according to reviewers' comments, language editing, laboratory facility, funds, etc. It will be helpful to minimize the gender biasness in quantification of authorship contribution of multi-authored research paper. PLOS ONE gave list of authors with detailed description on their contribution (Bendels et al., 2018). This qualitative information can be converted into quantitative, more transparent and unbiased gender sensitive knowledge.

Important observation noted by Cikara et al. (2012) that women publish less with slower annual growth but cited more in handbooks and textbooks. It indicates the sincerity, hard work and quality of women authors through the publication. No personal variables and editorial negotiation predict the publication productivity of women at top-publishers. Thus, the problem has deep roots in scientific world and needs re-evaluation with sound methodology (Bendels et al., 2018).

Since the last four decades, many policies are urging and guiding inclusion of women in research and publications. However, Geller et al. (2011) have reported no significant changes in status of women inclusion in clinical research from 2004. Further, the 'European Association of Science Editors (EASE)' has prepared the guidelines for reporting of 'Sex and Gender Equity in Research (SAGER)' and report writings. This guideline is for authors of research articles but helpful for reviewers and editors to design 'sex and gender' responsive policy and conduct editorial processes for gender equalities (Heidari et al., 2016).

Japan has patriarchy based social structure and strong sense. Japan ranked at fifth in high-productive countries (Phillips, 2016) with fewer female (17\%) representations (Bendels et al., 2018). The positive efforts can change this situation. For example, 
continuous inclusive efforts of 'Nature' have significantly enhanced women authorship from $12 \%$ in 2012 to $26 \%$ in 2017 and reviewers from $12 \%$ (2011) to $16 \%$ (2017) (Nature, 2018). Therefore, ice breaking policies should be prepared and implemented to strengthen the women for scientific publications. The discussions and findings presented in the paper will be useful to prepare and implement this type of policies.

\section{ABBREVIATIONS}

EASE: European Association of Science Editors; EC: Equal Contribution; GGRL: Gender in the Global Research Landscape; NRC: National Research Council; PCI: $\quad$ Percent-Contribution-Indicated; QUAD: Quantitative Uniform Authorship Declaration; SAGER: Sex and Gender Equity in Research; SDC: SequenceDetermines-Credit; STEMM: Science, Technology, Engineering, Mathematics and Medicine.

\section{ACKNOWLEDGEMENTS}

Author is thankful to anonymous reviewers for constructive comments and suggestions on the manuscript.

\section{CONFLICT OF INTEREST}

The author confirms that the content in this article has no conflict of interest.

\section{REFERENCES}

Addis, E. and Villa, P., 2003. The editorial boards of italian economics journals: Women, gender, and social networking. Fem Econ. 9(1), 75-91. DOI: https://doi.org/10.1080/1354570032000057062

Bart, C. and McQueen, G., 2013. Why women make better directors. Int J Bus Gov Ethics. 8(1), 93-99. DOI: https://doi.org/10.1504/IJBGE.2013.052743

Bendels, M. H. K., Müller, R., Brueggmann, D. and Groneberg, D. A., 2018. Gender disparities in high-quality research revealed by Nature Index journals. PLoS ONE, 13(1), e0189136. DOI: https://doi.org/10.1371/journal.pone.0189136

Besselaar, van den P., and Sandström, U., 2016. Gender differences in research performance and its impact on careers: A longitudinal case study. Scientometrics, 106(1), 143-162. DOI: https://doi.org/10.1007/s11192-015-1775-3

Bian, L., Leslie, S.-J. and Cimpian1, A., 2017. Gender stereotypes about intellectual ability emerge early and influence children's interests. Science, 355, 389-391. https://doi.org/10.1126/science.aah6524

Bornmann, L., Bauer, J., Haunschild, R., 2015. Distribution of women and men among highly cited scientists. J Assoc Inf Sci Technol, 66(12), 2715-2716. DOI: https://doi.org/10.1002/asi.23583

Brinker, A., Liao, J., Kraus, K., Young, J., Sandelski, M., Mikesell, C., Robinson, D., Adjei, M., Lunsford, S., Fischer, J., Kacena, M., Whipple, E. and Loder, R., 2018. Bibliometric analysis of gender authorship trends and collaboration dynamics over 30 years of Spine 1985 to 2015. SPINE, 43(14), E849-E854. DOI: https://doi.org/10.1097/BRS.0000000000002562

Buckley, H. L., Sciligo, A. R., Adair, K. L., Case, B. S. and Monks, J. M., 2014. Is there gender bias in reviewer selection and publication success rates for the New Zealand Journal of Ecology? New Zealand Journal of Ecology, 38(2), 335-339.

Budden, A. E.,Tregenza, T., Aarssen, L. W., Koricheva, J., Leimu, R. and Lortie, C. J., 2008. Double-blind review favours increased representation of female authors. TRENDS in Ecology and Evolution, 23(1), 4-6. https://doi.org/10.1016/j.tree.2007.07.008

Caplar, N., Tacchella, S. and Birrer, S., 2017. Quantitative evaluation of gender bias in astronomical publications from citation counts. Nature Astronomy, 141. DOI: https://doi.org/10.1038/s41550-017-0141

Ceci, S. J. and Williams, W. M., 2011. Understanding current causes of women's underrepresentation in science. PNAS, 108(8), 3157-3162. DOI: https://doi.org/10.1073/pnas.1014871108

Cho, A. H., Johnson, S. A., Schuman, C. E., Adler, J. M., Gonzalez, O., Graves, S. J., Huebner, J. R., Marchant, D. B., Rifai, S. W., Skinner, I. and Bruna, E. M., 2014. Women are underrepresented on the editorial boards of journals in environmental biology and natural resource management. PeerJ, 2, e542. DOI: https://doi.org/10.7717/peerj.542

Cikara, M., Rudman, L. and Fiske, S., 2012. Dearth by a thousand cuts? Accounting for gender differences in top-ranked publication rates in Social Psychology. The Journal of social issues. 68(2), 263-285. DOI: https://doi.org/10.1111/j.15404560.2012.01748.x

Cole, S. and Zuckerman, H., 1984. The productivity puzzle: Persistence and change in patterns of publication of men and women scientists. Advances in Motivation and Achievement, 2, 217 258.

Conley, D. and Stadmark, J., 2012. A call to commission more women writers. Nature, 488, 590. DOI: https://doi.org/10.1038/488590a

Davenport, 2014. Studying gender in conference talks data from the 223rd meeting of the American Astronomical Society, Zenodo. DOI: https://doi.org/10.5281/zenodo.14705

Dijk, Van D., Manor, O. and Carey, L. B., 2014. Publication metrics and success on the academic job market. Current Boiogy, 24(11), DOI: https://doi.org/10.1016/j.cub.2014.04.039

Duch, J., Zeng, X. H. T., Sales-Pardo, M., Radicchi, F., Otis, S, Woodruff, T. K. and Amaral, L. A. N., 2012. The possible role of resource requirements and academic career-choice risk on gender differences in publication rate and impact. PLoS ONE, 7(12), e51332. DOI: https://doi.org/10.1371/journal.pone.0051332 
Fadeel, B., 2009. But many that are first shall be last; and the last shall be first. The FASEB Journal, 23(5), 1283. DOI: https://doi.org/10.1096/fj.090503LTR

Figg, W. D., Dunn, L., Liewehr, D. J., Steinberg, S. M., Thurman, P. W., Barrett, J. C. and Birkinshaw, j., 2006. Scientific collaboration results in higher citation rates of published articles. Pharmacotherapy. 26(6), 759-767. DOI: https://doi.org/10.1592/phco.26.6.759

Filardo, G., da Graca, B., Sass, D. M., Pollock, B. D., Smith, E. B. and Martinez, M. A., 2016. Trends and comparison of female first authorship in high impact medical journals: Observational study (1994-2014). BMJ, 352, i847. DOI: https://doi.org/10.1136/bmj.i847

Fox, C. W., Burns, C. S. and Meyer, J. A., 2016. Editor and reviewer gender influence the peer review process but not peer review outcomes at an ecology journal. Func. Ecol., 30(1), 140-153. DOI: https://doi.org/10.1111/1365-2435.12587

Geller, S. E., Koch, A., Pellettieri, B. and Carnes, M., 2011. Inclusion, analysis, and reporting of sex and race/ethnicity in clinical trials: Have we made progress? J Womens Health (Larchmt), 20(3), 315320. DOI: https://doi.org/10.1089/jwh.2010.2469

GGRL [Gender in the Global Research Landscape], 2017. Gender in the Global Research Landscape, report by Elsevier.

Ghiasi, G., Larivière, V. and Sugimoto, C. R., 2015. On the compliance of women engineers with a gendered scientific system. PLoS ONE, 10(12), e0145931.

DOI: https://doi.org/10.1371/journal.pone.0145931

Gu, A., Almeida, N., Cohen, J. S., Peck, K. M. and Merrell, G. A., 2017. Progression of Authorship of Scientific Articles in The Journal of Hand Surgery, 1985-2015. J Hand Surg Am., 42(4), 291.e1291.e6.

DOI: https://doi.org/10.1016/j.jhsa.2017.01.005

Haws, B., Khechen, B., Movassaghi, k., Yom, K., Guntin, J., Cardinal, K., Shoshana, N. and Singh, K., 2018. Authorship trends in spine publications from 2000 to 2015. SPINE. 43(17), 1225-1230. DOI: https://doi.org/10.1097/BRS.0000000000002585

Heidari, S., Babor, T. F., De Castro, P., Tort, S. and Curno, M., 2016. Sex and gender equity in research: rationale for the sager guidelines and recommended use. Research Integrity and Peer Review, 1(2), 1-9. DOI: https://doi.org/10.1186/s41073-016-0007-6

Helmer, M., Schottdorf, M., Neef, A. and Battaglia, D., 2017. Gender bias in scholarly peer review, eLife, 6, e21718. DOI: https://doi.org/10.7554/eLife. 21718

Hill, C., Corbett, C. and St Rose, A., 2010. Why so few? Women in Science, Technology, Engineering, and Mathematics. American Association of University Women.
Holman, L., Stuart-Fox, D. and Hauser, C. E., 2018. The gender gap in science: How long until women are equally represented? PLoS Biol, 16(4), e2004956. DOI: https://doi.org/10.1371/journal.pbio.2004956

Jagsi, R., Guancial, E. A., Worobey, C. C., Henault, L. E., Chang, Y., Starr, R., Tarbell, N. J. and Hylek, E. M., 2006. The "gender gap" in authorship of academic medical literature - A 35-year perspective. $N$ Engl J Med, 355, 281-287. DOI: https://doi.org/10.1056/NEJMsa053910

James, D., and Drakich, J., 1993. Understanding gender differences in amount of talk: A critical review of research. In D. Tannen (Ed.), Oxford studies in sociolinguistics. Gender and Conversational Interaction (281-312). New York, NY, US: Oxford University Press.

Kaufman, R. R. and Chevan, J., 2011. The gender gap in peer-reviewed publications by physical therapy faculty members: A productivity puzzle. Physical Therapy, 91(1), 122-131. DOI: https://doi.org/10.2522/ptj.20100106

Kegen, N. V., 2013. Science networks in cutting-edge research institutions: Gender homophily and embeddedness in formal and informal networks. Procedia- Soc. Behav Sci., 79,62-81. DOI: https://doi.org/10.1016/j.sbspro.2013.05.057

Kyvik, S. and Teigen, M., 1996. Child care, research collaboration, and gender differences in scientific productivity. Sci Technol Human Values. 21(1), 54-71.

DOI: https://doi.org/10.1177/016224399602100103

Larivière, V., Vignola-Gagne', E. Villeneuve, C., Ge'linas, P. and Gingras, Y., 2011. Sex differences in research funding, productivity and impact: An analysis of Que'bec university professors. Scientometrics. 87(3), 483-498. DOI: https://doi.org/10.1007/s11192-011-0369-y

Larivière, V., Ni, C., Gingras, Y., Cronin, B. and Sugimoto, C. R., 2013. Global gender disparities in science. Nature, 504, 211-213. DOI: https://doi.org/10.1038/504211a

Lax Martínez, G., Raffo, J., Saito, K., 2016. Identifying the gender of PCT inventors. WIPO Economics \& Statistics Series, 33. Geneva, Switzerland: WIPO; 2016.

Lerback, J., Hanson, B., 2017. Journals invite too few women to referee. Nature, 541, 455-457. DOI: https://doi.org/10.1038/541455a

Liang, T., Zhang, C., Khara, R. M. and Harris, A. C., 2015. Assessing the gap in female authorship in Radiology: Trends over the past two decades. Journal of the American College of Radiology: JACR. 12(7), 735-741. DOI: https://doi.org/10.1016/j.jacr.2015.03.008

Long, J. S., 1992. Measures of sex differences in scientific productivity. Social Forces, 71(1), 159178. DOI: https://doi.org/10.1093/sf/71.1.159

Long, M. T., Leszczynski, A., Thompson, K. D., Wasan, S. K. and Calderwood, A. H., 2015. Female authorship in major academic gastroenterology 
journals: A look over 20 years. Gastrointestinal endoscopy, 81(6), 1440-1477.e3. DOI: https://doi.org/10.1016/j.gie.2015.01.032

Mauleón, E., Hillán, L., Moreno, L., Gómez, I. and Bordons, M., 2013. Assessing gender balance among journal authors and editorial board members. Scientometrics, 95(1), 87-114. DOI: https://doi.org/10.1007/s11192-012-0824-4

Mavriplis, C., Heller, R., Beil, C., Dam, K., Yassinskaya, N., Shaw, M. and Sorensen, C., 2010. Mind the gap: Women in STEM career breaks. J. Technol. Manag. Innov., 5(1), 141-151. DOI: https://doi.org/10.4067/S071827242010000100011

Mengel, F., Sauermann, J. and Zölitz, U., 2019. Gender bias in teaching evaluations. Journal of the European Economic Association, 17(2), 535-566. DOI: https://doi.org/10.1093/jeea/jvx057

Metz, I. and Harzing, A. W., 2009. Gender diversity in editorial boards of management journals. Acad Manag Learn Edu. 8(4), 540-557. DOI: https://doi.org/10.5465/AMLE.2009.47785472

Morton, M. J. and Sonnad, S. S., 2011. Women on professional society and journal editorial boards. $J$ Natl Med Assoc. 99(7), 764-771.

Moss-Racusin, C. A., Dovidio, J. F., Brescoll, V. L., Graham, M. J. and Handelsman, J., 2012. Science faculty's subtle gender biases favor male students. PNAS, 109 (41), 16474-16479. DOI: https://doi.org/10.1073/pnas.1211286109

Mueller, C. M., Gaudilliere, D. K., Kin, C., Menorca, R. and Girod, S., 2016. Gender disparities in scholarly productivity of US academic surgeons. Journal of Surgical Research, 203(1), 28-33. DOI: http://dx.doi.org/10.1016/j.jss.2016.03.060

Nature, 2018. Editorial: Nature's under-representation of women. Nature, 558, 344. DOI: https://doi.org/10.1038/d41586-018-05465-7

Nehere, K., 2017. The feminist views: A review. Feminist Research, 1(1), 3-20. DOI: https://doi.org/10.21523/gcj2.16010101

NRC [National Research Council], 2010. Gender differences at critical transitions in the careers of Science, Engineering, and Mathematics faculty. Washington, DC: The National Academies Press. DOI: https://doi.org/10.17226/12062

Ouyang, D., Sing, D., Shah, S., Hu, J., Duvernoy, C., Harrington, R. A. and Rodriguez, F., 2018. Sex disparities in authorship order of Cardiology scientific publications-trends over 40 years. Circulation: Cardiovascular Quality and Outcomes, 11, e005040. DOI: https://doi.org/10.1161/CIRCOUTCOMES.118.00 5040

Patat, F. and Schwarzschildstr, K., 2016. Gender systematics in telescope time allocation at ESO. Physics and Society, arXiv:1610.00920

Phillips, N., 2016. Nature Index 2016 Japan. Nature. 531(7594), S97. DOI: https://doi.org/10.1038/531S97a
Pritchard, J., Masters, K., Allen, J., Contenta, F., Huckvale, L. Wilkins, S. and Zocchi, A., 2014. Asking gender questions, Astronomy \& Geophysics, 55(6), 6.8-6.12. DOI: https://doi.org/10.1093/astrogeo/atu245

Rahman, M. T., Regenstein, J. M, Kassim, M. L. A. and Haque, N., 2017. The need to quantify authors' relative intellectual contributions in a multi-author paper. Journal of Informetrics, 11(1), 275-281. DOI: https://doi.org/10.1016/j.joi.2017.01.002

Ramos, A. M. G., Cortés, J. N. and Moreno, E. C., 2015. Dancers in the dark: Scientific careers according to a gender-blind model of promotion. Interdisciplinary Science Reviews, 40(2), 182-203. DOI:https://doi.org/10.1179/0308018815Z.000000 000112

Sheltzer, J. M. and Smith, J. C., 2014. Elite male faculty in the life sciences employ fewer women. PNAS, 111(28), 10107-10112. DOI: https://doi.org/10.1073/pnas.1403334111

Shen, H., 2013. Inequality quantified: Mind the gender gap. Nature, 495 (7439), 22-24. DOI: https://doi.org/10.1038/495022a

Stack, S., 2004. Gender, children and research productivity. Research in Higher Education, 45(8), 891-920. DOI: https://doi.org/10.1007/s11162004-5953-z

Stegmaier, M., Palmer, B. and van Assendelft, L., 2011, Getting on the board: The presence of women in political science journal editorial positions. Pol Sci and Pol. 44(04), 799-804. DOI: https://doi.org/10.1017/S1049096511001284

Topaz, C. M. and Sen, S., 2016. Gender representation on journal editorial boards in the mathematical sciences. PLoS ONE, 11(8), e0161357. DOI: https://doi.org/10.1371/journal.pone.0161357

Tregenza, T., 2002. Gender bias in the refereeing process? Trends in Ecology and Evolution, 17(8), 349-350. DOI: https://doi.org/10.1016/S01695347(02)02545-4

Tscharntke, T., Hochberg, M. E., Rand, T. A., Resh, V. H. and Krauss, J., 2007. Author sequence and credit for contributions in multiauthored publications. PLoS Biol, 5(1), e18. DOI: https://doi.org/10.1371/journal.pbio.0050018

Uhly, K. M., Visser, L. M., Zippel, K. S., 2017. Gendered patterns in international research collaborations in academia. Stud High Educ. Studies in Higher Education, 42, 760-782. DOI: https://doi.org/10.1080/03075079.2015.1072151

Verhagens, J. V., Wallace, K. J., Collins, S. C. and Thomas, T. R., 2003. QUAD system offers fair shares to all authors. Nature, 426, 602. DOI: https://doi.org/10.1038/426602a

Weltzien, J. F., Belote, R. T., Williams, L. T., Keller, J. F. and Engel, E. C., 2006. Authorship in ecology: Attribution, accountability, and responsibility. Front Ecol Environm, 4, 435-441. DOI: https://doi.org/10.1890/1540-9295 (2006)4[435:AIEAAA]2.0.CO;2 
West, J. D., Jacquet, .J, King, M. M., Correll, S. J. and Bergstrom, C. T., 2013. The role of gender in scholarly authorship. PLoS ONE, 8(7), e66212. DOI: https://doi.org/10.1371/ journal.pone.0066212

Williams, W. M., 2017. Editorial: Underrepresentation of women in science: International and crossdisciplinary evidence and debate. Front Psychol., 8 , $1-3$.

DOI: https://doi.org/10.3389/fpsyg.2017.02352

Wuchty, S., Jones, B. F. and Uzzi, B., 2007. The increasing dominance of teams in production of knowledge. Science, 316, 1036-1039. DOI: https://doi.org/10.1126/science.1136099

Zeng, X. H. T., Duch, J., Sales-Pardo, M., Moreira, J. A. G., Radicchi, F., Ribeiro, H. V., Woodruff, T. K., Amaral, L. A. N., 2016. Differences in collaboration patterns across discipline, career stage, and gender. PLoS Biol, 14(11): e1002573. DOI: https://doi.org/10.1371/journal.pbio.1002573

Zuckerman, H., 1968. Patterns of name ordering among authors of scientific papers: A study of social symbolism and its ambiguity. American Journal of Sociology, 276291. 